\title{
Uncapacitated Pricing Optimization for Mobile Broadband Services
}

\author{
Fransiscus Rian Pratikto ${ }^{1}$
}

\begin{abstract}
This research seeks to determine the optimal price for mobile broadband services of a particular service provider. The case study is mobile broadband services in the Indonesian market. We made a plausible assumption that there is no capacity constraint. We used choicebased conjoint with hierarchical Bayes estimation method to derive individual part-worth utilities, based on which market simulation was run to obtain the share-of-preference function. By combining this with information about market size, we came up with data points representing the demand function. Instead of fitting the data points with some theoretical demand functions, we used monotonic cubic splines to interpolate the demand function. Accordingly, we did not use explicit demand functions in the optimization, but a numerical interpolation function to estimate demand for any particular price level. Using enumeration, we then came up with a recommended contribution-maximizing prices under one, two, and three fare-classes segmentation. We assumed a perfect segmentation where cannibalization and arbitrage were not present. Single-segment pricing optimization came up with an optimal price of $\mathrm{Rp} 135,200$ with a total contribution of Rp1,106,902,315,961. Increasing the number of fareclass to two has improved the total contribution by $21,23 \%$, while the three fare-class resulted in a further 50\% increase in total contribution compared to that of the two fare-class. Further, we discussed a generalized optimal segmentation problem under the same assumption. We also investigated the impact of changes in competitors' service attributes on the optimal prices.
\end{abstract}

Keywords: Uncapacitated pricing optimization; choice-based conjoint; hierarchical Bayes; demand function; monotonic cubic splines.

\section{Introduction}

It has been more than three decades after the success of American Airlines implementing the first revenue management (or yield management) initiative in the mid-1980s that pricing and revenue optimization have become more tactical and operational. Pricing optimization, capacity allocation, and network management have been the central topics in this field, and statistics and operations research had been important tools for analysis (Phillips [1]). The success story of American Airlines resulted in widespread of revenue management initiatives across many industries, including telecommunication industry.

Research on pricing optimization in telecommunication industry is sparse. Most of these few focused on dynamic pricing and covered voice service, i.e. Keon and Anandalingam [2], Bouhtou et al. [3], and Dorgham et al. [4]. Keon and Anandalingam [2] developed a two-stage pricing mechanism which is dynamic pricing that gives a discount based on the system congestion. Bouhtou et al. [3] solved a pricing decision problem for voice service based on the

\footnotetext{
1 Factulty of Industrial Technology, Department of Industrial Engineering, Parahyangan Catholic University, Jl. Ciumbuleuit 94, Bandung 40141, INDONESIA. Email: frianp@unpar.ac.id

* Corresponding author
}

network condition using mixed-integer programming, while Dorgham et al. [4] developed a model of dynamic pricing based on the quality of service (QoS) for voice service using Monte Carlo simulation and meta-heuristics. Research that focused on wireless/mobile service is one by Yang and $\mathrm{Ng}$ [5] which developed nonlinear mixed-integer programming for product and service bundling problem which gives discounts on the price of the product based on the price of the service.

Mobile broadband is one of the most popular telecommunication services in a retail market. In Indonesia, mobile broadband service is offered with a flat monthly tariff under a particular QoS, usually regarding maximum speed and data quota. This research seeks to determine the optimal price for particular mobile broadband service. The case study is mobile broadband services in the Indonesian market. We assume that service provider does not have a capacity constraint. This assumption is plausible since increasing capacity to a certain level can be done very easily and fast. We used willingness-to-pay (WTP) approach and choice-based conjoint (CBC) method to derive part-worth utilities for each respondent, based on which a market simulation was run to obtain some data points which represent the share-of-preference function. Other research that used conjoint analysis to estimate WTP for telecommunication services is one by Klein and Jakopin [6], which used limit conjoint analysis to estimate WTP for service bundle. 
Using the share-of-preference function and information about the size of the market, we came up with data points for the demand function. Once we have data points representing the demand function, two approaches can be used to incorporate them into the optimization. The first approach is to fit the data with a particular theoretical demand function and estimate its corresponding parameters. The reader can refer to Huang et al. [7] for a comprehensive survey on the demand functions, both deterministic and stochastic. If demand is assumed to be deterministic, the least-squares method can be used to estimate the parameters of the function of interest. If we assume stochastic demand, we can use the Kalman filter (Kalman [8]) combined with a maximum likelihood function (Tommaso and Alessandra, [9) to estimate the parameters of the demand function. The advantage of this approach is that the demand function directly used in the optimization. The drawback is that we usually come up with a function that is not perfectly fit with the data. Another issue is that for a particular situation some demand function is not realistic, e.g. constantelasticity demand function is infinite and not satiating. Hence, to obtain a perfect fit, instead of fitting the data points with some general demand function, we used monotonic cubic splines to interpolate the demand function. Accordingly, we did not use explicit demand functions in the optimization, but a numerical interpolation function to estimate demand for any particular price level.

The objective function of the optimization problem was to maximize total contribution from all fare classes. The number of fare classes was predetermined and limited up to three, and the corresponding class boundaries were subjectively determined.

In marketing literature, prices are set around three primary considerations, i.e. cost, customers, and competitors, which lead to the so-called cost-plus, customer-driven, and share-driven pricing (Nagle et $a l$. [10]). The approach to pricing that we propose in this paper balances these three aspects of pricing. Cost is accommodated as incremental cost in the pricing optimization formulation, while customers and competitors go into the pricing optimization through the demand function. Through a market simulation, the points of demand data obtained to accommodate the effect of competition. The market simulation runs under a particular competitive scenario where some competitors are present with their corresponding levels of service attributes. The service attributes level changed by competitors will affect the demand function assessed by running the market simulation under the new scenario.

\section{Methods}

In this section, we describe three main methods used in this research, i.e. pricing optimization without capacity constraints, choice-based conjoint and hierarchical Bayes estimation method, and interpolating demand functions.

\section{Uncapacitated Pricing Optimization Problem}

Suppose a mobile broadband service provider faces a demand function $d(p)$ for a particular service and a particular customer segment, where $p$ is the monthly charge for the usage of the service. The uncapacitated contribution-maximizing price with one fare class can be obtained using

$\max _{p} m(p)=d(p)(p-c)$

where $m(p)$ is the total contribution and $c$ is the incremental cost (Phillips [1]). Incremental cost is an additional cost incurred by a producer for one additional customer. In multiple fare problem with $n$ fare classes, the maximization problem becomes

$\max _{p_{1}, \ldots, p_{n}} m\left(p_{1}, \ldots, p_{n}\right)=\sum_{i=1}^{n} d\left(p_{i}\right)\left(p_{i}-c\right)$

Using basic calculus, by assuming independence between fare classes, the maximum total contribution will be achieved when the optimal price for each fare class, $p_{i}^{*}$, satisfies

$d\left(p_{i}^{*}\right)=-d^{\prime}\left(p_{i}^{*}\right)\left(p_{i}^{*}-c\right)$

The optimization will be much more complicated when there are imperfect segmentations in the form of cannibalization and arbitrage.

In this research, we used WTP approach to derive demand functions. Using this notion, demand function, $d(p)$, was estimated from

$d(p)=D \int_{p}^{\infty} w(x) d x$

where $D$ is the size of the market segment and $w(x)$ is the WTP function. We assumed myopic consumers who buy as soon as the offered price is less than their WTP (Talluri and van Ryzin [11]). The first component of the demand function, $D$, was estimated as total market size multiplied by market segment proportion. For the second component, instead of deriving $w(x)$ and taking the corresponding integral, we used $\mathrm{CBC}$ and market simulation to come up with estimated values of $\int_{p}^{\infty} w(x) d x$. 


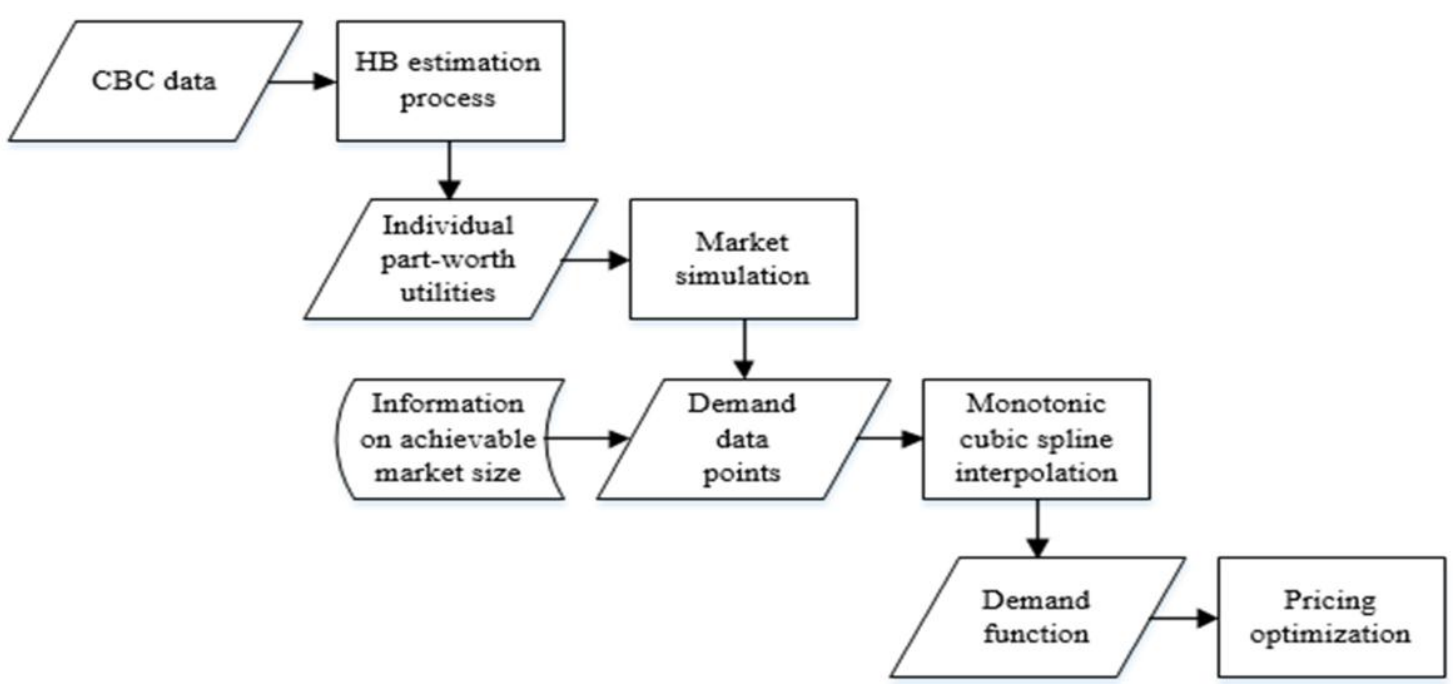

Figure 1. Methodology to estimate demand function from CBC data for pricing optimization

Figure 1 shows how CBC data is used to estimate price-response or demand function for pricing optimization.

The methodology combines three methods that are considered robust, i.e., HB estimation (Sawtooth Software [12]), market simulation based on randomized first choice (Orme and Baker [13]), and monotonic cubic spline interpolation (Wolberg and Alfy [14]). The following two subsections describe those three in detail.

\section{Choice-Based Conjoint and the Hierarchical Bayes Estimation Method}

Jedidi and Jagpal [Error! Reference source not found.] argued that-compared to other methods for deriving WTP function such as using actual purchase data, self-stated WTP, contingent valuation methods (CVM), and experimental auction-CBC is the best method for determining demand function in a competitive setting. In a CBC study, consumers are repeatedly asked to choose between some stimuli in randomly generated choice sets. Each choice set is made realistic by adding a 'none' option. A CBC questionnaire consists of some choice sets (usually 12-18). Consumer preferences can be estimated from these choice data using logit, latent class, or hierarchical Bayes method (Orme [0]).

$\mathrm{CBC}$ experiment is realistic since it resembles the way consumers make decisions in the market. It is also less biased compared to other conjoint methods as it puts the less informational burden on the respondents. The only weakness associated with $\mathrm{CBC}$ is the existence of hypothetical bias. Hypothetical bias is bias due to the hypothetical nature of choice set in the CBC questionnaire. This bias is common to all stated preference methods. Discussion on the causes of and remedies for hypothetical bias in $\mathrm{CBC}$ can be found in Orme and Chrzan [17].

Our CBC study design used five attributes following the result from Amelia [18], i.e. provider, payment method, data quota, speed, and monthly price. There are $5,2,5,5$, and five levels for each attribute, respectively. Instead of conducting a CBC survey, we used choice data from Susanta [19] which used the same attributes and levels as in Amelia [18].

We used hierarchical Bayes (HB) to estimate consumer preferences from $\mathrm{CBC}$ data. HB, which produces utility estimates at an individual level with good accuracy (Orme [0]), has two stages of estimation. At the upper stage, HB estimates part-worth utilities for each respondent, while at the lower stage HB estimates the probability of each respondent choosing a certain stimulus (Sawtooth Software, Inc., [12]). HB assumes that the part-worth utilities of each respondent, $\boldsymbol{\beta}_{i}$, follow a multivariate normal distribution with a mean vector of $\boldsymbol{\mu}$, and a covariance matrix of $\boldsymbol{\Sigma}$. The value of $\boldsymbol{\beta}_{i}, \boldsymbol{\mu}$, and $\boldsymbol{\Sigma}$ can be estimated using recursive process employing the Cholesky decomposition and the MetropolisHastings algorithm until the values of those three converge (see Figure 2).

Once we have the individual part-worth utilities, the probability of choosing a particular alternative $k$, is governed by the multinomial logit model

$p_{k}=\frac{\mathrm{e}^{\mathrm{x}_{\mathrm{k}}^{\prime} \beta_{\mathrm{i}}}}{\sum_{\mathrm{j}=1}^{\mathrm{n}} \mathrm{e}^{\mathbf{x}_{j}^{\prime} \beta_{\mathrm{i}}}}$

In the above formula $p_{k}$ is the probability that a respondent chooses the $k$ th concept in a particular choice task, while $\mathbf{x}_{\mathbf{k}}^{\prime}$ and $\mathbf{x}_{\mathrm{j}}^{\prime}$ is the row vector of the $k$ th and $j$ th stimuli in the choice task. 


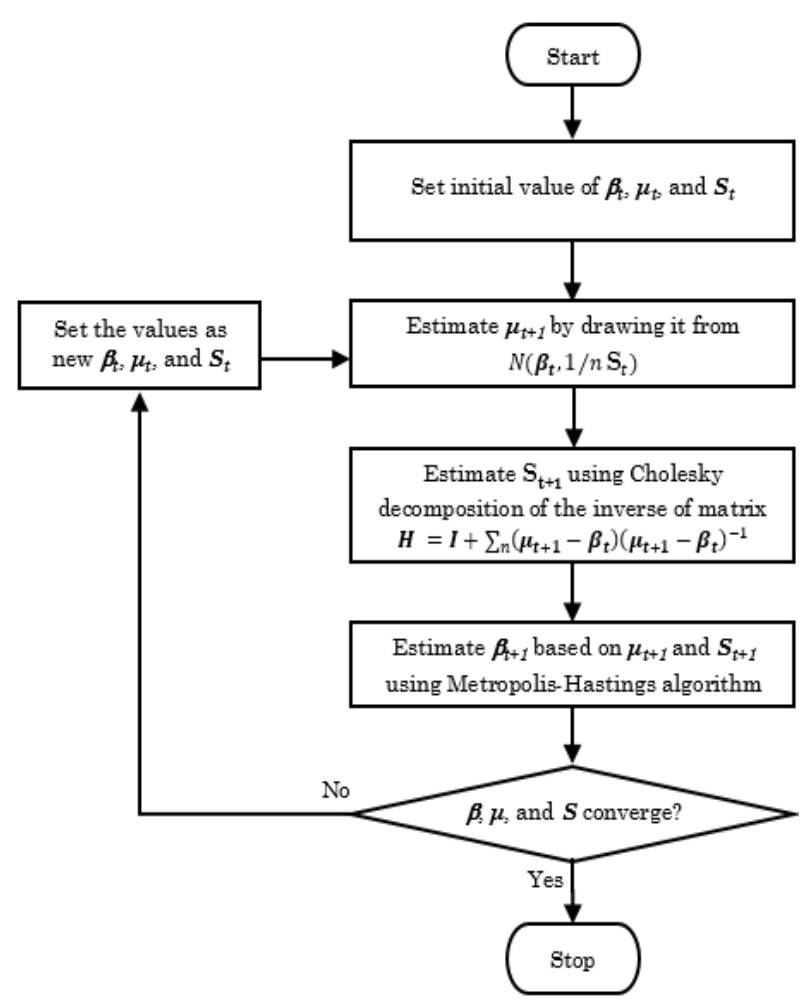

Figure 2. Hierarchical Bayes estimation method

We used Sawtooth Software CBC/HB to estimate part-worth utilities from CBC data using hierarchical Bayes method.

The use of CBC with HB estimation method, which results in the part-worth utilities at an individual level, enables us to run a market simulation with any scenario that we are interested in. The output of the simulation is the proportion of the respondents that would choose a stimulus of interest called share of preference. If the respondents are representative of the market, then this share of preference would be the estimate of market share. This simulation feature would be very useful in product design and development and marketing research.

The market simulator calculates the estimated share of preferences using the randomized first choice method (Huber et al. [20]). This method adds two random elements to the utility of stimulus $i$ for respondent $j, U_{i j}$, i.e. product variability, $\boldsymbol{E}_{p}$, and choice variability, $E_{f}$, both are assumed to be of Gumbel distribution (Orme and Baker [13]). Then, we have

$U_{i j}=\boldsymbol{x}_{i}^{\prime}\left(\boldsymbol{\beta}_{j}+\boldsymbol{E}_{p}\right)+E_{f}$

The share of preference for stimulus $i$ in choice set $S$ is calculated as the aggregation of choice probability of each respondent

$P_{j}=P\left(U_{i j} \geq U_{k j}, \forall k \in S\right)$
We used Sawtooth Software SMRT to run the market simulation from individual part-worth utility data. Using individual part-worth from each respondent, we can estimate the share of preference for each product concept in any given scenario. When the simulation runs for a given scenario under varied price levels, we will have some data points for our demand function, which later will be interpolated to obtain the demand function.

\section{Interpolating the Demand Function}

In this research, we assume that demand is deterministic. Under a deterministic assumption, if we cannot find one demand function that fit all the demand data points, it is very intuitive to think that maybe we can find some functions that, when combined to form one continuous function, fit all the demand data points. This is the basic idea of the spline interpolation method. In addition to the continuity property, a demand function has to be non-increasing (Phillips [1]) motivating us to use the monotonic cubic spline interpolation (Wolberg and Alfy [14]) to interpolate the demand function.

In our case, suppose we have $n$ demand data points $\left\{\left[p_{0}, d_{0}\right],\left[p_{1}, d_{1}\right], \ldots,\left[p_{\mathrm{n}-1}, d_{\mathrm{n}-1}\right]\right\}$, and let $f_{k}(p)=d_{k}$ be the function defined for interval $\left[p_{k-1}, p_{k}\right]$. This method aims to find a piecewise cubic polynomial, $f(p)$ consisted of $n-1$ sections that fit all $n$ demand data points. Constraints on the continuity of $f^{\prime}\left(p_{k}\right)$ and $f^{\prime \prime}\left(p_{k}\right)$ are imposed to ensure continuity over the range of $p$. Accordingly, $f_{k}(p)$ has the following form

$$
\begin{aligned}
f_{k}(p)= & q_{k}\left(p-p_{k}\right)^{3}+r_{k}\left(p-p_{k}\right)^{2} \\
& +s_{k}\left(p-p_{k}\right)+t_{k}
\end{aligned}
$$

where $\quad q_{k}=\frac{1}{\Delta p_{k}^{2}}\left(-2 \frac{\Delta d_{k}}{\Delta p_{k}}+d_{k}^{\prime}+d_{k+1}^{\prime}\right), \quad r_{k}=$ $\frac{1}{\Delta p_{k}}\left(3 \frac{\Delta d_{k}}{\Delta p_{k}}-2 d_{k}^{\prime}-d_{k+1}^{\prime}\right), s_{k}=d_{k}^{\prime}$, and $t_{k}=d_{k}$. The reader can refer to Wolberg and Alfy [14] for a complete formulation of the monotonicity condition. This approach guarantees the fitness of the demand function with all demand data points. The disadvantage of this approach is the complexity of the optimization formulation if we are to use the explicit polynomial functions of the demand. Instead of embedding explicit demand functions into the optimization, we use numerical interpolation based on those polynomial demand functions.

\section{Results and Discussions}

\section{Demand Function}

We used choice data from 231 respondents who were collected from an online survey using Sawtooth Software SSI Web v7.0.30 by Susanta [19]. The CBC questionnaire consists of fifteen choice tasks out of 
which thirteen choice tasks are random, and two choice tasks are fixed. The fixed choice tasks were used later to assess the validity of the estimated part-worth utilities. Each choice task contains three product concepts and one 'none' option with the fullprofile presentation. Table 1 presents the attributes and levels of the $\mathrm{CBC}$ questionnaire.

Each respondent answered a different set of questions which were randomly generated by the software in such a way that the overall questionnaires are balanced, orthogonal, and have minimum overlaps (Chrzan and Orme [21]). Some prohibitions were also made in the questionnaire design to prevent the occurrence of improbable product concept, such as one with superior quality attributes but low price.

Sawtooth Software CBC HB v5.5.4 was used to run the HB estimation method. The output of the HB estimation indicated that the parameter estimation had converged and was about $70 \%$ of a perfect fit. A root likelihood of 0.659 indicated that the resulted part-worth utility was $0.659 / 0.250=2.636$ times better in predicting respondent's choice compared to a random guess. We also tested the internal validity of the HB estimates by comparing actual choices from the fixed choice tasks with those predicted by the part-worth utilities. Table 2 presents the result of internal validity test using the first fixed choice task.

We obtained a mean absolute error (MAE) of 6.53\% which, for our choice task design (each consisted of three stimuli and one 'none' option), corresponds to a mean absolute percentage error (MAPE) of $6.53 \% /$ $25 \%=26.12 \%$. Using the same procedure on the second fixed choice task, we got a MAPE of $25.74 \%$. Hence, the average MAPE of those two fixed choice tasks was $25.93 \%$ suggests that the model had a relatively low accuracy, which may be due to small sample size. The academic license that we used in this research limits the number of data that runs in the estimation procedure to a maximum of 250 , but incomplete data and limited time that the previous researcher had in conducting the survey (Susanta, [19]) resulted in only 231 data were eligible for estimation.

Using the respondent's utilities as input, we ran the market simulator Sawtooth Software SMRT v4.23 to get the price-response curve. The simulation was run under a scenario where there were five products (all are prepaid) with the following configurations: (1) Provider A - 2GB, 7.2 Mbps, Rp90,000; (2) Provider B - 2GB, 7.2 Mbps, Rp50,000; (3) Provider C 500MB, 7.2 Mbps, Rp50,000; (4) Provider D - 8GB, 768 Kbps, Rp90,000; and (5) Provider E - 5GB, 3.1 Mbps, Rp90,000.
Table 1. Attributes and levels of the $\mathrm{CBC}$ questionnaire

\begin{tabular}{ll}
\hline \multicolumn{1}{c}{ Attributes } & \multicolumn{1}{c}{ Levels } \\
\hline Provider & Provider A; Provider B; Provider C; \\
& Provider D; Provider E \\
Payment method & Prepaid; Postpaid \\
Data quota & 500MB; 2GB; 5GB; 8GB; 10GB \\
Maximum speed & $768 \mathrm{kbps}$ 1.8Mbps; 3.1Mbps; \\
& $7.2 \mathrm{Mbps}$ 14.4Mbps \\
Monthly price & Rp50,000; Rp90,000; \\
& Rp130,000; Rp250,000; \\
& Rp450,000 \\
\hline
\end{tabular}

Table 2. Internal validity test using first fixed choice task

\begin{tabular}{lccc}
\hline $\begin{array}{l}\text { Stimuli of the } \\
\text { 1st fixed choice } \\
\text { task }\end{array}$ & $\begin{array}{l}\text { Actual shares } \\
\text { of preference }\end{array}$ & $\begin{array}{l}\text { Simulated } \\
\text { shares of } \\
\text { preference }\end{array}$ & $\begin{array}{l}\text { Absolute } \\
\text { errors }\end{array}$ \\
\hline Stimulus 1 & $9.09 \%$ & $19.62 \%$ & $10.53 \%$ \\
Stimulus 2 & $10.39 \%$ & $7.48 \%$ & $2.91 \%$ \\
Stimulus 3 & $46.75 \%$ & $36.61 \%$ & $10.14 \%$ \\
None & $33.77 \%$ & $36.29 \%$ & $2.52 \%$ \\
\hline \multicolumn{4}{r}{} \\
\hline
\end{tabular}

This scenario represented the real competitive market condition when conducted the survey. Since we were to optimize pricing tactic for Provider A, we simulated by varying the price of Provider A while keeping other attributes constant. Five data points were obtained from the simulation. Two data points were added subjectively, one indicating the share of preference when the price is zero, and one indicating the satiating price. Satiating price is the price at which demand drops to zero (Phillips [1]).

To get a demand curve in term of a number of customers, we multiplied the share of preference with the estimated size of the market segment. From the market survey conducted by the Association of Indonesia Internet Service Providers in 2016, there are about 130.3 million consumers that have mobile internet access [22], while from the research conducted by PT. Telekomunikasi Indonesia, Tbk., it was estimated that $43.49 \%$ of mobile service customers are in the low-end segment [23]. Hence, there are about 56.67 million customers in this market segment. By multiplying the share of preference with the estimated size of the market segment resulted in the demand data points. Table 3 presents all demand data points3.

To estimate demand for those data points we used the free SRS1 Microsoft Excel add-in which has an elementary function to return the demand given any price level. This function has three arguments, i.e. source data of the predictor variable, source data of the predicted variable, and the value of the predictor variable whose predicted variable we wish to estimate. Figure 3 depicts the demand curve interpolated using this function. 
Table 3. Demand data points for Provider A

\begin{tabular}{lccccccc}
\hline Price (Rps) & 0 & 50,000 & 90,000 & 130,000 & 250,000 & 450,000 & 600,000 \\
Share of preference & $100 \%$ & $44.71 \%$ & $27.66 \%$ & $18.59 \%$ & $8.28 \%$ & $3.88 \%$ & $0 \%$ \\
Demand (millions) & 56.67 & 25.34 & 15.67 & 10.53 & 4.69 & 2.19 & 0 \\
\hline
\end{tabular}

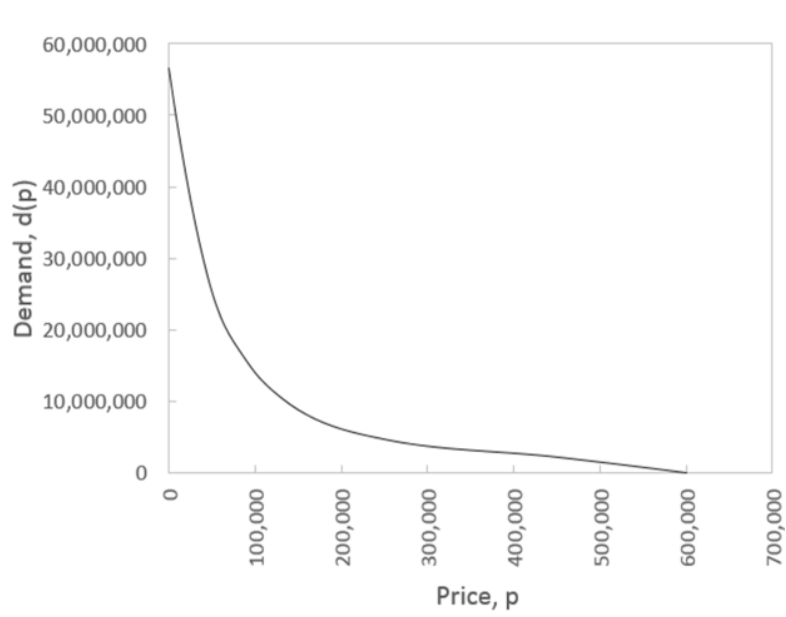

Figure 3. The demand curve for Provider A

\section{Pricing Optimization with One Fare-Class}

The complete formulation of the uncapacitated pricing optimization with one fare class is as follows:

$$
\max _{p} m(p)=d(p)(p-c)
$$$$
\text { s.t. } 0 \leq p \leq 600,000
$$

Since we did not have the explicit functions of the demand, we used an enumeration to solve the optimization problem. Assuming the incremental cost to be Rp 25,000 and using a step-value of Rp 100 for the decision variable, we came up with the optimal price of $\operatorname{Rp} 135,200$. At this price level, the demand is $10,044,486$ with a total contribution of Rp 1,106,902,315,961.

\section{Pricing Optimization with Two Fare-Classes}

Two fare-class pricing optimization requires two demand functions, one for each segment. For the two fare-class problems we divided the market into two segments based on the demand elasticity value. This segmentation was a plausible assumption in segregating the market and was equivalent to differentiating between consumers that have elastic (elasticity greater than 1) and those with inelastic demand (elasticity smaller than 1). We calculated the elasticity for every price interval of Rp100 and took an elasticity value of one as the cutoff. We found that the cutoff point corresponds to the price level of Rp88,400. We assumed further that the segregation of the segments was perfect which means that there was no cannibalization and arbitrage. Cannibalization happens when customers in high-price segments find a way to pay the lower price, while arbitrage happens when price differentials make a

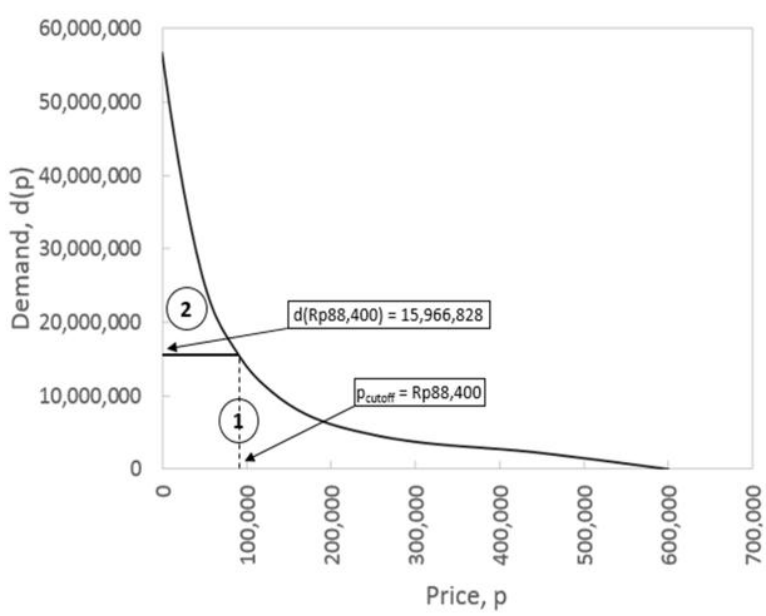

Figure 4. Splitting demand function into two fare-classes

third-party arbitrageurs find a way to buy the product at the low price and resell it to customers with high WTP at a below-the-market price, and keeping the difference as a profit for themselves (Phillips [1]). Using these conditions, we split the demand function into two separated segments as depicted in Figure 4.

Segment 1 consists of consumers with elastic demand which correspond to those that have higher WTP, while segment 2 are consumers with inelastic demand and correspond to those with lower WTP. Accordingly, we had demand function for segment one as follows:

$d_{1}\left(p_{1}\right)=\min \left(d\left(p_{1}\right), 15966828\right)$

moreover, the demand function for segment 2 was as follows

$d_{2}\left(p_{2}\right)=\max \left(d\left(p_{2}\right)-15966828,0\right)$

The optimization problem for the two fare-classes became

$\max _{p_{1}, p_{2}} m\left(p_{1}, p_{2}\right)=\min \left(d\left(p_{1}\right), 15966828\right)\left(p_{1}-\right.$

$c)+\max \left(d\left(p_{2}\right)-15966828,0\right)\left(p_{2}-c\right)$

s.t. $88400<p_{1} \leq 600,000,0 \leq p_{2} \leq 88,400$

Assuming the same incremental cost and step-value, by using enumeration, we came up with the optimal price of Rp135,200 for segment 1 and Rp48,500 for segment 2 with corresponding total contribution of Rp 1,106,902,315,961 and Rp 234,949,822,549, respectively. Total contribution for two fare-class is $\mathrm{Rp}$ $1,341,852,138,511$, a $21.23 \%$ increase compared to that of single fare-class. 


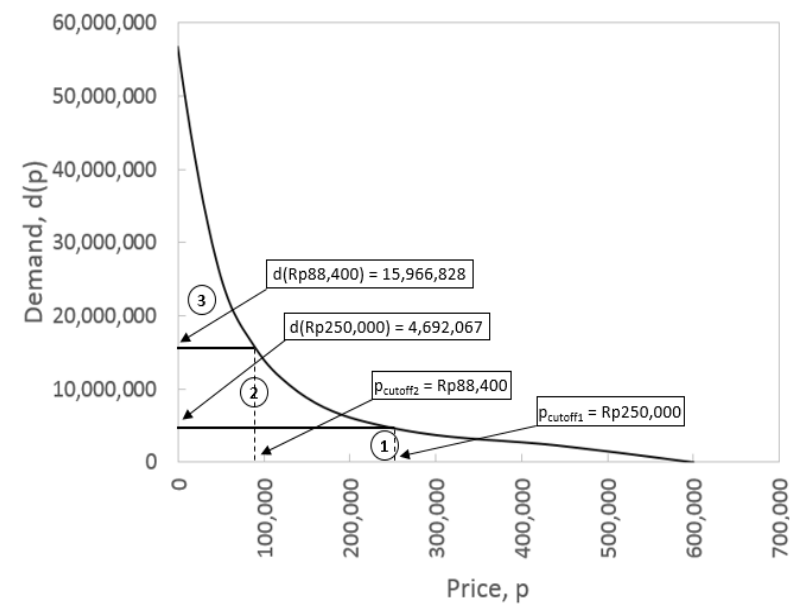

Figure 5. Splitting demand function into three fareclasses.

\section{Pricing Optimization with Three Fare-Classes}

For the three fare-class pricing optimization, we divided the market as follows: segment 1 were customers with WTP > Rp 250,000, segment 2 were those with $\mathrm{Rp} 88,400<\mathrm{WTP} \leq \mathrm{Rp} 250,000$, and segment 3 were those with WTP $<$ Rp 88,400. Referring to market segregation in the two fare-classes problems, what we did was splitting the higher WTP segment into two segments while keeping the lower WTP segment as it was.

Figure 5 depicts the split of the demand functions into three segments. The corresponding demand functions were $d_{1}\left(p_{1}\right)=\min \left(d\left(p_{1}\right), 4692067\right)$, $d_{2}\left(p_{2}\right)=\min \left(d\left(p_{2}\right)-4692067,11274762\right), \quad$ and $d_{3}\left(p_{3}\right)=\max \left(d\left(p_{3}\right)-15966828,0\right)$ for segment 1 , segment 2, and segment 3, respectively. Accordingly, follows is the pricing formulated optimization problem

$$
\begin{gathered}
\max _{p_{1}, p_{2}, p_{3}} m\left(p_{1}, p_{2}, p_{3}\right)=\min \left(d\left(p_{1}\right), 4692067\right)\left(p_{1}-c\right) \\
+\min \left(d\left(p_{2}\right)-4692067,11274762\right)\left(p_{2}-c\right) \\
\quad+\max \left(d\left(p_{3}\right)-15966828,0\right)\left(p_{3}-c\right) \\
\text { s.t. } 250000<p_{1} \leq 600000,88400<p_{2} \leq \\
\text { 250000, } 0<p_{3} \leq 88400
\end{gathered}
$$

Using the same procedure, we came up with optimal price of $\operatorname{Rp} 250,000$ for segment $1, \operatorname{Rp} 88,500$ for segment 2, and Rp 48,500 for segment 3, with total contribution of $\mathrm{Rp} 1,055,714,966,100$,

Rp 714,819,897,552, and $\operatorname{Rp} 234,949,822,549$ for segment 1 , segment 2 , and segment 3 , respectively. The total contribution from all classes was $\mathrm{Rp}$ $2,005,484,686,201$, an almost $50 \%$ increase compared to that of the two fare-class.

\section{Optimal Segmentation}

Our findings supported the theoretical assertion that higher number of segment results in higher total contribution. In practice, the limit to segmentation is the feasibility to implement it without imperfections (e.g. cannibalization and arbitrage). In our optimization problems, boundaries between segments were given. In fact, this parameter does affect the total contribution. If we are to consider these boundaries as decision variables in the pricing optimization, the optimization problem becomes much more extensive. Suppose we divide customers into $n$ mutually exclusive and independent segments such that $W T P_{1}>W T P_{2}>\cdots>W T P_{n}$, and define the boundaries, $v_{i}$, such that $v_{i+1}<W T P_{i} \leq v_{i}$ for $i=1, \ldots, n-2$ and $0<W T P_{n} \leq v_{n-1}$. Then, the formulation for optimal segmentation with $n$ segment is as follows

$$
\begin{aligned}
& \underset{\left(p_{1}, p_{2}, \ldots, p_{n} ; v_{1}, v_{2}, \ldots, v_{n-1}\right)}{\quad} m\left(p_{1}, p_{2}, \ldots, p_{n} ; v_{1}, v_{2}, \ldots, v_{n-1}\right) \\
& +\min \left(d\left(p_{1}\right), d\left(v_{1}\right)\right)\left(p_{1}-c\right) \\
& +\min \left(d\left(p_{2}\right)-d\left(v_{1}\right), d\left(v_{2}\right)-d\left(v_{1}\right)\right)\left(p_{2}-c\right) \\
& +\cdots \\
& +\min \left(d\left(p_{n-1}\right)-d\left(v_{n-2}\right), d\left(v_{n-1}\right)-\right. \\
& \left.d\left(v_{n-2}\right)\right)\left(p_{n-1}-c\right) \\
& +\max \left(d\left(p_{n}\right)-d\left(v_{n-1}\right)\right)\left(p_{n}-c\right) \\
& \text { s.t. } v_{i+1}<p_{i} \leq v_{i}, i=1, \ldots, n-2 ; 0<p_{n} \leq v_{n-1}
\end{aligned}
$$

The size of this optimization problem depends mostly on the number of fare-class. If we are to solve this problem using our approach (enumeration with nonexplicit demand function), the size of the discrete solution space will also be affected by the price grid. If we divide the price continuum into $m$ grids and divide customers into $n$ segments, the number of alternative solutions that have to be evaluated is about $m^{n}$.

\section{What-if Analysis}

What would happen if competitors change the levels of their product attributes? We picked one scenario as an illustration and suggested that other scenarios can be analyzed in a similar way. Suppose that the strongest competitor, Provider C, changed its quotaprice combination from the current level of $2 \mathrm{~GB}-\mathrm{Rp}$ 50,000 to $5 \mathrm{~GB}-\mathrm{Rp} 90,000$, and we were to analyze how it affects the optimal price. We ran a market simulation based on a new scenario that incorporates this change. Table 4 depicts the data points resulted from the simulation. Using these new data points, we estimated the new demand function using the monotonic cubic spline interpolation and then embedded it into the optimization as in equation 8.

In the one fare-class pricing optimization we came up with an optimal price of Rp 111,700 and the corresponding total contribution of $\mathrm{Rp} 923,827$, 567,833 , a $16.54 \%$ decrease compared to that of the scenario without the changes. 
Table 4. Demand data points for provider after provider C's changes

\begin{tabular}{lccccccc}
\hline Price (Rps) & 0 & 50,000 & 90,000 & 130,000 & 250,000 & 450,000 & 600,000 \\
Share of preference & $100 \%$ & $38.88 \%$ & $24.33 \%$ & $15.38 \%$ & $5.89 \%$ & $2.84 \%$ & $0 \%$ \\
Demand (millions) & 56.67 & 22.03 & 13.79 & 8.72 & 3.34 & 1.61 & 0 \\
\hline
\end{tabular}

This illustration shows the benefit of using CBC with $\mathrm{HB}$ estimation method in deriving demand for pricing optimization. The individual level part-worth utility values and market simulation capability give us flexibility in assessing any probable scenario that we might face in the market. This is useful in situations where markets are dynamic, and competitors may frequently change the level of their products' attributes. A drawback of this approach is that we can only simulate scenarios regarding levels of attributes that we have defined earlier (discrete levels). It is not possible to choose a level value somewhere in between (continuous level). This can be accommodated using continuous price in the CBC questionnaire design, but it comes at a price. See Orme [24] for further discussion on the pros and cons of using continuous price in CBC study

\section{Conclusion}

In this research, we developed an uncapacitated pricing optimization model for mobile broadband services in which the estimated demand function from CBC data. Using hierarchical Bayes estimation method and market simulation, some data points that represent the demand function were obtained from the CBC data. The demand function was then estimated from the data points using monotonic cubic spline interpolation. Instead of using an explicit demand function, we embedded the demand function into the optimization using numerical interpolation. This approach was quite flexible that the impact of any changes in the levels of the service's attributes (of both ours and our competitors) and other mode parameters on the optimal prices could be assessed and estimated easily by running the market simulation under the revised scenario.

For single fare-class pricing, we obtained an optimal price of $\operatorname{Rp} 135,200$ with a total contribution of $R p$ $1,106,902,315,961$, while for two fare-class problems we got optimal prices of Rp135,200 for a higher-WTP

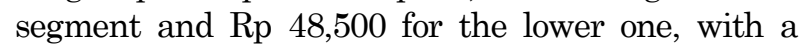
total contribution of $\operatorname{Rp} 1,341,852,138,511$, a $21.23 \%$ increase compared to that of the single fare-class. For the three fare-class problems we came up with the optimal price of Rp 250,000 for high-WTP, Rp 88,500 for medium-WTP, and Rp48,500 for the lowWTP segment, with a total contribution of $\mathrm{Rp}$ $2,005,484,686,201$, a $50 \%$ increase compared to that of the two fare-class.

Despite its flexibility, the model that we developed has some limitations. For multi-segment pricing, it was assumed that the segmentation was perfect where cannibalization and arbitrage were not pre- sent. In the real world, perfect segmentation is usually difficult to achieve. In such situation, a more comprehensive model that incorporates those imperfections is needed. It was also assumed that the demand was deterministic, while in the real world that is not the case. The information needed to incurporate uncertainty in the pricing optimization model can be obtained from the output of the market simulation. The output of market simulation gives us not only information about the estimated share of preferences but also a standard error of those estimates. This information enables us to simulate the demand and calculate the corresponding optimal prices. These two issues (segmentation imperfection and demand uncertainty) will be the agenda for our future research.

\section{References}

1. Phillips, R. L., Pricing and Revenue Optimization, Stanford University Press, Stanford, 2005.

2. Keon, N. and Anandalingam, G., A New Pricing Model for Competitive Telecommunications Services using Congestion Discounts, INFORMS Journal on Computing, 17(2), 2005, pp. 248-262.

3. Bouhtou, M., Medori, J-R., and Minoux, M., Mixed Integer Programming Model for Pricing in Telecommunication, 5th International Network Optimization Conference, Springer, Hamburg, 2011, pp.626-630.

4. Dorgham K., Saleh M., and Atiya A.F., A Novel Dynamic Pricing Model for the Telecommunications Industry, in Modelling, Computation and Optimization in Information Systems and Management Sciences. Advances in Intelligent Systems and Computing, Le Thi H., Pham Dinh T., Nguyen N. (eds), vol 360. Springer, 2015.

5. Yang, B. and Ng, C. T., Pricing Problem in Wireless Telecommunication Product and Service Bundling, European Journal of Operational Research, 207, 2010, pp. 473-480.

6. Klein, A. and Jakopin, N., Consumers' Willingness-To-Pay for Mobile Telecommunication Service Bundles, Telematics and Informatics, 31, 2014, pp. 410-421.

7. Huang, J., Leng, M., and Parlat, M., Demand Functions in Decision Modeling: A Comprehensive Survey and Research Directions, Decision Sciences, 44(3), 2013, pp. 557-609.

8. Kalman, R. E., A New Approach to Linear Filtering and Prediction Problems, Journal of Basic Engineering, 82(D), 1960, pp. 35-45. 
9. Tommaso, P. dan Alessandra, L., Maximum Likelihood Estimation of Time Series Models: the Kalman Filter and Beyond, in Handbook of Research Methods and Applications in Empirical Macroeconomics, Hashimzade, N. dan Thornton, M. A., (eds). Northampton, MA: Edward Elgar Publishing, Inc, 2013.

10. Nagle. T. T., Hogan, J. E., and Zale, J., The Strategy and Tactics of Pricing: A Guide to Growing More Profitably, Routledge, New York, 2011.

11. Talluri, K. T. and van Ryzin, G. J., The Theory and Practice of Revenue Management, Springer, 2004.

12. Sawtooth Software, The CBC/HB System for Hierarchical Bayes Estimation Version 5.0 Technical Paper, Technical Paper Series, Sawtooth Software, Inc., Sequim, 2009.

13. Orme, B. K. and Baker, G., Comparing Hierarchical Bayes Draws and Randomized First Choice for Conjoint Simulations, Sawtooth Software Conference Proceedings, 2000, pp. 239-254.

14. Wolberg, G. and Alfy, I., An Energy-Minimization Framework for Monotonic Cubic Spline Interpolation, Journal of Computational and Applied Mathematics, 143, 2002, pp. 145-188.

15. Jedidi, K and Jagpal, S., Willingness To Pay: Measurement and Managerial Implications, in Handbook of Pricing Research in Marketing, Rao, V. R., (eds), Edward Elgar, Cheltenham, 2009.

16. Orme, B. K., Getting Started with Conjoint Analysis: Strategies for Product Design and Pricing
Research, $2^{\text {nd }}$ ed., Research Publishers, Chicago, 2010.

17. Orme, B. K. and Chrzan, K., Becoming an Expert in Conjoint Analysis: Choice Modeling for Pros, Sawtooth Software, Inc., Orem, 2017.

18. Amelia, Penentuan Atribut Layanan Mobile Internet Menggunakan Choice-Based Conjoint Analysis, Skripsi, Jurusan Teknik Industri, Universitas Katolik Parahyangan, 2011.

19. Susanta, L. N., Usulan Penetapan Harga untuk Paket Mobile Internet Telkomsel Flash Berdasarkan Choise-Based Conjoint Analysis, Skripsi, Jurusan Teknik Industri, Universitas Katolik Parahyangan, 2013.

20. Huber, J., Orme, B. K., and Miller, R., Dealing with Product Similarity in Conjoint Simulation, Sawtooth Software Conference Proceedings, 1999, pp. 253-266.

21. Chrzan, K. and Orme, B. K., An Overview and Comparison of Design Strategies for ChoiceBased Conjoint Analysis, Sawtooth Software Research Paper Series, 2000.

22. APJII, Penetrasi \& Perilaku Pengguna Internet Indonesia 2016, Survey Report, Association of Indonesia Internet Service Providers, 2016.

23. Telkom MCC, Riset Positioning Flexi dan Telkomsel, Research Report, Management Consulting Center PT. Telekomunikasi Indonesia, Tbk., Unpublished, 2007.

24. Orme, B. K., Three Ways to Treat Overall Price in Conjoint Analysis, Research Paper Series, Sawtooth Software, Inc., Sequim, 2007. 